\title{
Profile and Antibiotic Susceptibility Pattern of Bacterial Isolates from Mobile Phones of Healthcare Workers in a Tertiary Care Centre of Nepal
}

\author{
Jyotshna Sapkota1, Beena Jha1, Bhavesh Mishra1, Deepti Shrestha², Achut Barakoti , Manisha \\ Sharma ${ }^{1}$ \\ 1Department of Microbiology, Kathmandu Medical College and Teaching Hospital, Sinamangal, Kathmandu, \\ Nepal, '2Department of Pharmacology, Nepal Medical College and Teaching Hospital, Jorpati, Kathmandu, \\ Nepal, ${ }^{3}$ Department of Microbiology, Nepal Medical College and Teaching Hospital, Jorpati, Kathmandu, Nepal
}

\section{Corresponding author:}

Jyotshna Sapkota, MBBS, MD

Department of Microbiology, Kathmandu Medical College and Teaching Hospital, Sinamangal, Kathmandu, Nepal Email:21jyots@gmail.com

Submitted : Jun 6, 2020

Accepted : July 26, 2020

\begin{abstract}
Introduction

Nosocomial infection is a serious problem worldwide. Healthcare workers mobile phones may act as vehicle for nosocomial infections. Mobile phones are rarely cleaned and healthcare workers frequently use them thorough out their time in hospitals. The objective of this study is to determine the rate of contamination of mobile phones, prevalent microorganisms and their antibiotic sensitivity pattern.
\end{abstract}

\section{Methods}

The descriptive cross-sectional study was carried out in Clinical Microbiology laboratory from July 2019 to September 2019 after ethical approval. Samples were collected aseptically by rolling sterile swabs over the exposed surfaces of the mobile phones and inoculated on the agar plates and incubated aerobically. After incubation, plates were examined for growth. Bacteria were identified by standard microbiological procedure and antibiotic sensitivity test of isolated pathogens was done using Muller Hinton Agar by Kirby-Bauer method. Statistical analysis was done by Excel 2018.

\section{Results}

Of the 198 mobile phones sample cultures, 112 (56.6\%) samples showed 7 different types of bacteria. Mixed growth was observed in 3 mobile phones and total of 115 bacterial isolates were identified. Staphylococcus species (74.7\%) were predominant organism followed by Acinetobacter spp, Klebsiella pneumoniae, E. coli, Citrobacter and Pseudomonas aeruginosa. Total 37.5\% of Staphylococcus aureus were methicillin-resistant Staphylococcus aureus (MRSA).

\section{Conclusion}

Mobile phones may have potential pathogenic microorganisms on their surface and can act as vector in spread of infectious agents in hospital settings. It is recommended to disinfect mobile phones regularly and to implement hand washing practices and regulations around the use of mobile phones in hospital settings.

Keywords: Acinetobacter species, mobile phones, MRSA, nosocomial infections, Staphylococcus species 


\section{INTRODUCTION}

$\mathrm{H}$ ealth care-associated infections (HCAls) or nosocomial infections are one of the commonest adverse events affecting patients while receiving health care. ${ }^{1}$ Many studies suggest hands of healthcare workers (HCWs) play pivotal role in transmission of HCAls. ${ }^{2} \mathrm{HCW}^{\prime}$ hands are often contaminated with pathogenic microorganisms through exogenous source of infections. ${ }^{3}$

Mobile phones which have become indispensable part of our life often provide a reservoir of exogenous source of HCAls in hospitals. Mobile phones are often used by HCWs without restrictions and proper hand hygiene practices. ${ }^{4} \mathrm{HCW}$ s take their mobile phones everywhere including operation theatre, intensive care units, wards, postoperative care units, use them while attending patients and are rarely cleaned, thus serving as a vehicle in transmission of nosocomial infections. ${ }^{5}$

Mobile phones are widely used in healthcare settings and may act as vector for transmission of $\mathrm{HCls}$. Microbial evaluation of such commonly used devices in healthcare settings should be done frequently. Thus, the objective of this study was to determine the degree of bacterial contamination and their resistance against commonly used antibiotics found on the HCWs mobile phones at Kathmandu Medical College.

\section{METHODS}

A hospital based descriptive cross sectional study was carried out in Clinical Microbiology Laboratory of Kathmandu Medical College and Teaching Hospital (KMCTH), Kathmandu Nepal from the month of July 2109 to September 2019. Ethical approval was received from Institutional Review Committee (Ref no. 150320195).

A total of $198 \mathrm{HCW}$ involved in patient management from intensive care unit, operation theatre, postoperative wards, different wards and laboratory were randomly selected as study participant were enrolled in the study after informed consent. Samples were collected aseptically by rolling sterile cotton swab moistened with normal saline over different surfaces of mobile phones are were transported to laboratory as soon as possible in a test tube with cotton plug. Samples were inoculated in Blood and MacConkey agar plates and incubated at 370C for 24 hours aerobically and were examined for growth. Identification of bacteria were done by standard bacteriological technique. ${ }^{6}$ Antimicrobial susceptibility of all isolates was determined by the standard Kirby Bauer disk diffusion method according to norms of Clinical Laboratory Standards Institute (CSLI). ${ }^{7}$ Data analysis was performed using Microsoft Excel.

\section{RESULTS}

Out of 198 mobile phones, 112 (56.56\%) mobile phones had bacterial colonization and no growth was seen in 86 (43.44\%) mobile phones (Fig:1). Mixed growth was observed in 3 mobile phones and total of 115 bacterial isolates were identified.

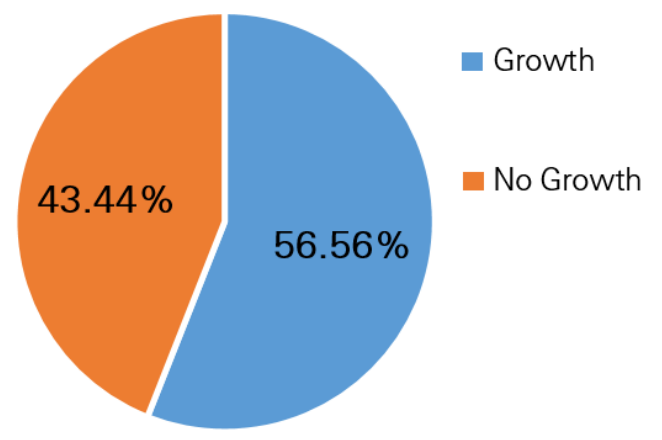

Fig 1. Bactreial contamination of HCW mobile phones

The types of bacteria isolated from mobile phones are summarized in Table 1. Coagulasenegative Staphylococcus (CoNS) were the predominant isolates [70 $(60.8 \%)]$. The rest were Staphylococcus aureus, Acinetobacter, E. coli, Klebsiella pneumoniae, Pseudomonas aeruginosa, Citrobacter.

Table 1. Type of bacteria isolated from HCW's mobile phones $(n=115)$

\begin{tabular}{lc}
\hline \multicolumn{1}{c}{ Bacteria isolated } & Number (\%) \\
\hline Coagulase-negative Staphylococcus & $70(60.8 \%)$ \\
Staph. aureus & $16(13.9 \%$ \\
Acinetobacter & $14(12.3 \%)$ \\
E. coli & $5(4.3 \%)$ \\
Klebsiella pneumonia & $6(5.3 \%)$ \\
Citrobacter & $2(1.7 \%)$ \\
Pseudomonas aeruginosa & $2(1.7 \%)$ \\
\hline
\end{tabular}

Table 2. Antibiotic sensitivity pattern of Gram positive cocci isolated from HCW's mobile phones $(n=86)$

\begin{tabular}{lcc}
\hline \multirow{2}{*}{ Antibiotics } & $\begin{array}{c}\text { CoNS } \\
(\mathbf{n = 7 0 )}\end{array}$ & $\begin{array}{c}\text { Staph. aureus } \\
(\mathbf{n}=16)\end{array}$ \\
\cline { 2 - 3 } & Sensitive no. (\%) & Sensitive no. (\%) \\
\hline Cefoxitin & $70(100 \%)$ & $10(62.50 \%)$ \\
Ciprofloxacin & $18(25.71 \%)$ & $6(37.50 \%)$ \\
Cotrimoxazole & $61(87.14 \%)$ & $12(75.00 \%)$ \\
Amikacin & $70(100 \%)$ & $14(87.50 \%)$ \\
Erythromycin & $23(32.86 \%)$ & $0(0 \%)$ \\
Clindamycin & $22(31.43 \%)$ & $7(43.75 \%)$ \\
Linezolid & $70(100 \%)$ & $16(100 \%)$ \\
\hline
\end{tabular}


Table 3. Antibiotic sensitivity pattern of Gram negative bacilli isolated from HCW's mobile phones $(n=86)$

\begin{tabular}{lccccc}
\hline \multirow{2}{*}{ Antibiotics } & $\begin{array}{c}\text { Acinetobacter } \\
(\mathbf{n}=14)\end{array}$ & $\begin{array}{c}\text { K. pneumoniae } \\
(\mathbf{n}=6)\end{array}$ & $\begin{array}{c}\text { E.coli } \\
(\mathbf{n}=5)\end{array}$ & $\begin{array}{c}\text { Citrobacter } \\
(\mathbf{n}=2)\end{array}$ & $\begin{array}{c}\text { P. aeruginosa } \\
(\mathbf{n}=2)\end{array}$ \\
\cline { 2 - 6 } & Sensitive no. (\%) & Sensitive no. (\%) & Sensitive no. (\%) & Sensitive no. (\%) Sensitive no. (\%) \\
\hline Amikacin & $11(78.6 \%)$ & $5(83.3 \%)$ & $5(100 \%)$ & $2(100 \%)$ & $2(100 \%)$ \\
Ampicillin & $0(0 \%)$ & $1(16.7 \%)$ & $0(0 \%)$ & $0(0 \%)$ & $0(0 \%)$ \\
Ciprofloxacin & $6(42.9 \%)$ & $5(83.3 \%)$ & $5(100 \%)$ & $2(100 \%)$ & $2(100 \%)$ \\
Ceftriaxone & $3(21.4 \%)$ & $4(66.7 \%)$ & $2(40 \%)$ & $1(50 \%)$ & $0(0 \%)$ \\
Cefixime & $3(21.4 \%)$ & $2(33.3 \%)$ & $1(20 \%)$ & $1(50 \%)$ & $0(0 \%)$ \\
Imipenem & $6(42.9 \%)$ & $5(83.3 \%)$ & $5(100 \%)$ & $2(100 \%)$ & $2(100 \%)$ \\
Piperacillin- & $7(50.0 \%)$ & $5(83.3 \%)$ & $4(80 \%)$ & $2(100 \%)$ & $2(100 \%)$ \\
Tazobactam & $4(100 \%)$ & $6(100 \%)$ & $5(100 \%)$ & $2(100 \%)$ & $2(100 \%)$ \\
Tegecycline & & & & & \\
\hline
\end{tabular}

The antibiogram of Gram positive cocci is shown in table 2. Total 37.5\% Staph. aureus were methicillinresistant Staphylococcus aureus (MRSA). Both CoNS and Staph. aureus were $100 \%$ susceptible to linezolid.

Antibiotic susceptibility pattern of gram negative bacilli is shown in Table 3. All gram negative bacilli are $100 \%$ sensitive to antibiotic tigecycline. Similarly, amikacin, ciprofloxacin and piperacillintazobactam is effective in E. coli, Citrobacter and P. aeruginosa. Acinetobacter and K. pneumoniae have variable sensitivity patterns.

\section{DISCUSSION}

HCWs plays important role in transmission of nosocomial infections. ${ }^{8}$ Microorganisms are transmitted from person to person or through fomites like stethoscope, elevator buttons, table surfaces, mobile phones, thermometer. Hand washing has been repeatedly shown to reduce the risk of HCAl. 9,10

The result of our study shows that mobile phones which are often used by HCWs in healthcare settings carry potentially pathogenic microorganisms. The frequency of contamination of mobile phones observed in this study was $56.56 \%$. Similar rate of contamination was found by Kokate et al and Mark et al. ${ }^{11,12}$ Whereas many other studies has shown higher rate of contamination of HCW's mobile phones. Overall, studies done across the world on mobile phones contamination has varied prevalence of $24 \%$ to $94.5 \% . .^{13-19}$ This variation in rate of contamination might be due to difference in adherence to infection control practices or frequency of disinfection of mobile phones and hand washing practices.

Out of 115 bacteria isolated in the study, Staphylococcus species $(74.7 \%)$ were predominant bacteria grown from HCWs mobile phones. Similar pattern has been observed and reported by various studies done in contamination of mobile phones. ${ }^{13}$
Balapriya $\mathrm{P}$ et al in her study of nosocomial pathogens in mobile phones showed that CoNS were mostly susceptible to Penicllin which is similar to our study. ${ }^{14}$ Normal skin flora primarily consist of gram positive cocci especially CoNS, this might be reason of their high rate and growth of fewer gram negative bacteria from mobile phones in present and other studies. It is also well known fact that organisms like S.aureus and CoNS resist dryness and thus can survive and multiply in warm environments like mobile phones. ${ }^{17}$

The second common bacteria isolated from HCWs mobile phones was Acinetobacter species (12.3\%). It is a gram negative cocco-bacillus. Isolation of Acinetobacter species from mobile phones is not unexpected given its ubiquitous nature and ability to persist in hospital environment for long period of time.

Isolation of multidrug resistant organisms like MRSA and Acinetobacter species from HCWs' mobile phone is a worrisome finding. The isolation of antibiotic-resistant bacteria from mobile phone is a serious issue with important implications for hospital infection prevention and control program.

\section{CONCLUSION}

Our study showed mobile phones used by HCWs were contaminated with potentially pathogenic bacteria. These microorganisms could be transmitted to patients through hands of HCWs. Some measures to prevent cross contamination through mobile phones like limited use of mobile phones in hospital settings, regular disinfection of mobile phones and hand washing is recommended.

\section{CONFLICT OF INTEREST}

None declared.

\section{REFERENCES}

1. Haque M, Sartelli M, McKimm J, Abu Bakar M. Health careassociated infections - an overview. Infect Drug Resist. 


\section{8;11:2321-33.}

2. Allegranzi B, Pittet D. Role of hand hygiene in healthcare-associated infection prevention. Journal of hospital infection. 2009;73(4):30515.

3. Morubagal RR, Shivappa SG, Mahale RP, Neelambike SM. Study of bacterial flora associated with mobile phones of healthcare workers and non-healthcare workers. Iranian Journal of Microbiology. 2017:9(3):143.

4. Pal S, Juyal D, Adekhandi S, Sharma M, Prakash R, Sharma N, et al. Mobile phones: Reservoirs for the transmission of nosocomial pathogens. Advanced biomedical research. 2015;4:144.

5. Misgana GM, Abdissa K, Abebe G. Bacterial contamination of mobile phones of healthcare workers at Jimma University Specialized Hospital, Jimma, South West Ethiopia. Int J Infect Control. 2014;11(1):1-8.

6. Isenberg HD. Clinical microbiology procedures handbook: American Society of Microbiology; 1992.

7. Wayne P. Clinical and Laboratory Standards Institute: Performance standards for antimicrobial susceptibility testing: Twenty-fourth informational supplement, M100-S24. Clinical and Laboratory Standards Institute (CLSI). 2014;34(1).

8. Khan HA, Baig FK, Mehboob R. Nosocomial infections: Epidemiology, prevention, control and surveillance. Asian Pacific Journal of Tropical Biomedicine. 2017;7(5):478-82.

9. Parry MF, Hutchinson JH, Brown NA, Wu C-H, Estreller L. Gramnegative sepsis in neonates: a nursery outbreak due to hand carriage of Citrobacter diversus. Pediatrics. 1980;65(6):1105-9.

10. Steere AC, Mallison GF. Handwashing practices for the prevention of nosocomial infections. Annals of Internal Medicine. 1975;83(5):683-90.
11. Kilic IH, Ozaslan M, Karagoz ID, Zer Y, Davutoglu V. The microbial colonisation of mobile phone used by healthcare staffs. Pak J Biol Sci. 2009 Jun 1;12(11):882-4.

12. Mark D, Leonard C, Breen H, Graydon R, O'Gorman C, Kirk S. Mobile phones in clinical practice: reducing the risk of bacterial contamination. Int J Clin Pract. 2014 Sep;68(9):1060-4.

13. Balapriya P, Padmakumari J, Vijayalakshmi A. Screening for nosocomial pathogens in stethoscopes, sphygmomanometers and mobile phones of health care providers in a tertiary care hospital. Int J Curr Microbiol App Sci. 2016;5(10):91-8.

14. Jayalakshmi J, Appalaraju B, Usha S. Cellphones as reservoirs of nosocomial pathogens. The Journal of the Association of Physicians of India. 2008;56:388.

15. Karkee $P$, Madhup $S$, Humagain $P$, Thaku N, Timilsina B. Mobile phone: A possible vector of bacterial transmission in hospital setting. Kathmandu Univ Med J. 2017;59(3):217-21.

16. Marwa A, Nadia M. Mobile phones are silent threat. Int J Curr Microbiol App Sci. 2015;4:199-205.

17. Neha $S$, Aruna $S$, Parihar $R$, Khatri $P$, Arvind C, Archana B. Prevalence and antibiotic pattern of microbes isolated from mobile phones of health care workers and non-health care workers. Int Curr Microbiol App Sci. 2014;3:43-60.

18. Ulger F, Esen S, Dilek A, Yanik K, Gunaydin M, Leblebicioglu H. Are we aware how contaminated our mobile phones with nosocomial pathogens? Annals of clinical microbiology and antimicrobials. 2009;8(1):7.

19. Trivedi HR, Desai KJ, Trivedi LP, Malek SS, Javdekar TB. Role of mobile phone in spreading hospital acquired infection: a study in different group of health care workers. Natl J Integr Res Med. 2011;2(3):61-6. 